\title{
Capacidade combinatória e heterose para resistência a pinta- preta em mamoeiro por meio de análise dialélica
}

\author{
Marcelo Vivas ${ }^{1}$, Silvaldo Felipe da Silveira ${ }^{1}$, Deisy Lúcia Cardoso², Messias Gonzaga Pereira², Pedro \\ Henrique Dias dos $\operatorname{Santos}^{1} \&$ Geraldo Antônio Ferreguetti ${ }^{3}$ \\ ${ }^{1}$ Laboratório de Entomologia e Fitopatologia; ${ }^{2}$ Laboratório de Melhoramento Genético Vegetal, Centro de Ciências e \\ Tecnologias Agropecuárias, Universidade Estadual do Norte Fluminense Darcy Ribeiro, 28015-620, Campos dos Goytacazes, \\ RJ, Brasil; ${ }^{3}$ Caliman Agrícola SA, 29.900-970, Linhares, ES, Brasil
}

Autor para correspondência: Marcelo Vivas, e-mail: mrclvivas@hotmail.com

\begin{abstract}
RESUMO
Foi realizado um cruzamento dialélico envolvendo oito genótipos de mamão, quatro do grupo 'Solo' e quatro do grupo 'Formosa'. As 56 combinações híbridas (F1 e recíprocos) juntamente com seus pais foram avaliados quanto à resistência à pinta-preta causada por Asperisporium caricae. Quantificou-se em duas épocas, março e maio de 2010, a severidade da pinta-preta em folhas e frutos. Com a média de cada característica foram estimadas, além da heterose, as capacidades geral e específica de combinação. Os genótipos 'JS12-N', 'Sekati', 'Golden' e 'Sunrise Solo 72/12' apresentaram melhor capacidade geral de combinação para as duas características. Doze híbridos apresentaram resultados promissores para seleção, com baixos valores de capacidade especifica de combinação para resistência à pintapreta, tanto em folhas quanto em frutos. Evidenciou-se efeito de heterose na cultura do mamoeiro para resistência à pinta-preta, com ganhos genéticos significativos advindos tanto de cruzamentos inter- como intragrupos heteróticos e, no segundo caso, especialmente entre genótipos do grupo 'Solo'.
\end{abstract}

Palavras-chave: Asperisporium caricae, Carica papaya, hibridação.

\begin{abstract}
Combining ability and heterosis for resistance to black-spot in papaya genotypes by diallel analysis

Diallelic crosses were performed between eight papaya genotypes belonging to the 'Solo' and 'Formosa' heterotic groups (four belonging to each group). The 56 hybrid combinations (F1's and reciprocals) along with their parents were evaluated in a complete randomized block design for resistance to black spot disease, caused by Asperisporium caricae. The severity of black spot in leaves and fruits was quantified in two occasions, March and May 2010. When the genotype effect was significant, heterosis as well as general and specific combining ability were estimated from the severity data. The genotypes 'JS12-N', 'Sekati', 'Golden' and 'Sunrise Solo 72/12' displayed better general combining ability for both characteristics. Twelve hybrids displayed promising results for selection, with low values of specific combining ability for resistance to black spot leaves and fruits. The heterotic group did not affect hybrid performance or heterosis estimates. Heterosis in papaya for resistance to black spot may provide significant genetic gains from both inter-and intraheterotic crosses, and especially from hybridizations involving genotypes of the 'Solo' group.
\end{abstract}

Key words: Asperisporium caricae, Carica papaya, hybridization.

\section{INTRODUÇÃO}

O mamoeiro (Carica papaya L.) é uma das fruteiras tropicais de grande importância no Brasil. Atualmente, o Brasil é o segundo maior produtor mundial, ficando atrás somente da Índia, e o terceiro maior exportador da fruta. O mamão é a sétima fruta "in natura" mais exportada no País, sendo cultivado em cerca de 30 mil hectares, que estão concentrados nos estados do Espírito Santo, Bahia, Ceará e Rio Grande do Norte (Agrianual, 2011). No Brasil e no mundo, há poucas variedades e híbridos comerciais que

Parte da Tese de Doutorado do primeiro autor. Universidade Estadual do Norte Fluminense Darcy Ribeiro. Campos dos Goytacazes RJ. atendam tanto ao mercado interno quanto ao externo e que agreguem além de características de alta produtividade e qualidade de frutos, a resistência a doenças.

Dentre as doenças de etiologia fúngica que acometem o mamoeiro, a pinta-preta, causada pelo fungo Asperisporium caricae (Speg.) Maubl., é a doença mais comum na maioria das regiões do mundo onde se cultiva o mamoeiro, tais como: África,Austrália e Oceania, sul e sudeste da Ásia(ex: Índia) e nas Américas Central e do Sul (Liberato et al., 2007). Atualmente, a pinta-preta é de expressiva importância econômica em todas as regiões onde ocorre, pois afeta o desenvolvimento da planta pela redução da área foliar quando em alta severidade, expressa pelo número elevado de lesões necróticas. Quando as lesões acometem os frutos, estes tornam-se inadequados à comercialização (Rezende \& Martins, 2005). Santos \& 
Barreto (2003) relatam perdas devido à pinta-preta de 30\% na comercialização de frutos de mamão em São Paulo. Segundo Liberato \& Zambolim (2002), plantas muito afetadas podem perder de 50 a $60 \%$ de suas folhas em um período de dois a três meses e a incidência da doença em frutos pode atingir quase $100 \%$.

As medidas de controle baseiam-se principalmente na aplicação de fungicidas e em práticas culturais, como remoção de folhas e restos de cultura (Suzuki et al., 2007). O uso da resistência genética para o controle da pinta-preta, bem como o melhoramento da cultura para seleção de genótipos resistentes esbarra na falta de cultivares e genótipos imunes a este fitopatógeno (Santos \& Barreto, 2003, Dianese et al., 2007, Vivas et al., 2011). Dianese et al. (2007), apontam a necessidade de trabalhos de melhoramento genético do mamoeiro que visem a obtenção de genótipos resistentes à pinta-preta.

Segundo Koutsika-Sotiriou \& Karagounis (2005), o sucesso em programas de melhoramento depende da existência de alta variabilidade, bem como da escolha acurada de populações com potencial considerável para a característica desejada. Dentre os métodos de estudo, os métodos de análise dialélica constituem uma estratégia que permite a identificação precoce de híbridos capazes de produzir uma progênie superior. Esta metodologia ainda é pouco utilizada na cultura do mamoeiro. Todavia, seu emprego por Marin et al. (2006) permitiu o registro no Ministério da Agricultura de nove híbridos. O primeiro deles 'UENF/CALIMAN01' (Calimosa), foi recomendado aos agricultores e vem sendo cultivado nas diferentes regiões produtoras do Brasil, nos Estados do Rio Grande do Norte, Bahia e Espírito Santo.

Apesar dos esforços dos programas de melhoramento do mamoeiro no Brasil, o país é importador de sementes de mamão, o que justifica a necessidade de se intensificar trabalhos de melhoramento nessa cultura, inclusive envolvendo a avaliação de genótipos quanto à resistência às doenças como a causada pelo fungo A caricae. Objetivou-se neste trabalho avaliar, por meio de cruzamentos dialélicos, as capacidades geral e específica de combinação (CGC e CEC) quanto à resistência a pinta-preta, bem como o efeito recíproco de oito genótipos de mamoeiro, quatro do grupo 'Solo' e quatro do grupo 'Formosa', com o intuito de se desenvolver cultivares e, ou híbridos de mamoeiro resistentes a esta doença.

\section{MATERIAL E MÉTODOS}

O experimento foi implantado no ano de 2009, em área da empresa Caliman Agrícola SA (Linhares, ES), em esquema de dialelo completo (Cruz \& Regazzi, 2011) entre oito genitores, quatro do grupo 'Formosa' ('Maradol', 'JS12-N', 'JS12-4' e 'Sekati') e quatro do grupo 'Solo' ('Waimanalo', 'Golden', 'Sunrise Solo 72-12' e 'São Mateus'). Todos os genitores pertencem ao banco de germoplamsa da UENF, mantido em parceria com a empresa Caliman Agrícola. Excetuando-se a cultivar 'Golden', os demais genitores são linhagens elites, não cultivados comercialmente no Brasil.
Foram avaliados 64 cruzamentos (Genitores, $\mathrm{F}_{1}$ 's e recíprocos) em delineamento estatístico em blocos ao acaso, com quatro repetições, sendo cada parcela composta de 10 plantas (duas fileiras de cinco plantas cada). O espaçamento entre plantas foi de $3,6 \times 2,0 \times 1,8 \mathrm{~m}$. Os tratos culturais, conforme rotina da empresa, foram: correção do $\mathrm{pH}$ e da saturação de bases do solo ( $\mathrm{V}=85 \%$ ); adubação em sulco de plantio a base de $150 \mathrm{~kg}$.ha- ${ }^{-1}$ de $_{2} \mathrm{O}_{5}$ e 10 litro.m $\mathrm{m}^{-1}$ de composto de esterco de galinha: boi (1:1); adubação em cobertura de $300 \mathrm{~kg}$ de N, $650 \mathrm{~kg}$ de $\mathrm{K} 20,80 \mathrm{~kg}$ de $\mathrm{P}_{2} \mathrm{O}_{5}, 90 \mathrm{~kg}$ de Ca e $30 \mathrm{~kg}$ de $\mathrm{Mg}$ via fertirrigação, sendo esta localizada e por microaspersão. Para controle de pragas e doenças foram feitas pulverizações conforme regime pluviométrico, a intervalos quinzenais (períodos chuvosos) e mensais (períodos secos), utilizando-se fungicidas e inseticidas registrados para cultura (MAPA/AGROFIT), até janeiro de 2010.

Quantificou-se a severidade da pinta-preta na folha (SPPFo) em três plantas e em duas ocasiões (março e maio de 2010), segundo metodologia adotada por Vivas et al. (2011), com auxílio de escala diagramática $(0,2 ; 1,6 ; 3,5 ; 5,4 ; 7,6$ e $12,8 \%$ de área foliar lesionada). A severidade da pinta-preta no fruto (SPPFr), no estágio 1 de maturação, foi estimada com base na escala diagramática para frutos com pinta-preta proposta por Vivas et al. (2010), com os valores de 0,$1 ; 0,3 ; 0,6 ; 1,2 ; 2,5 ; 5,0$; 10,0 e 20,0\% de área superficial lesionada.

Para cada variável foram conduzidas análises de variância conjuntas, considerando-se também a época de avaliação como fonte de variação. Quando constatado efeito significativo da interação genótipo $\mathrm{x}$ época, foram conduzidas análises separadas por época. As somas de quadrados só foram desmembradas em capacidade específica e geral de combinação quando constatado efeito significativo de genótipo. Nas análises de capacidade combinatória foram incluídos os genitores e os híbridos $\mathrm{F}_{1}$, com os recíprocos, perfazendo o total de $\mathrm{p}^{2}$ genótipos. Considerou-se para análise o Método 1, Modelo 1, de Griffing (1956). Todas as análises foram feitas utilizando o programa Genes (Cruz, 2006).

Com a média de cada tratamento efetuou-se também a estimativa de heterose e heterobeltiose para cada característica avaliada. Estimativa de heterose foi obtida pela expressão:

$H M P=\left(\frac{M H-M P}{M P}\right) * 100$

onde, $\mathrm{HMP}=$ heterose ou heterose média dos pais, $\mathrm{MH}=$ média do híbrido, e MP = média dos pais. Estimativa de heterobeltiose foi obtida pela expressão:

$H P S=\left(\frac{M H-P S}{P S}\right) * 100$

onde, $\mathrm{HPS}=$ heterobeltiose ou heterose pai superior, $\mathrm{MH}=$ média do híbrido, e PS = média do pai superior (Falconer, 1987).

\section{RESULTADOS E DISCUSSÃO}

Para as duas variáveis avaliadas, severidade da pintapreta em folhas e em frutos, observou-se efeito significativo 
de todas as fontes de variação testadas (genótipo, época de avaliação e interação entre os dois fatores). Desta forma, procederam-se análises individuais para cada época de avaliação. Com base nas análises de variância individuais observou-se, para pinta-preta em folha, efeito significativo de genótipo apenas na segunda época de avaliação. Portanto, apenas a segunda época foi considerada nas análises de capacidade combinatória (Tabela 1). Já, para a pinta-preta em fruto, observou-se efeito significativo de genótipo apenas na primeira época de avaliação. Portanto apenas a primeira época foi considerada nas análises de capacidade combinatória para severidade da pinta-preta em frutos (Tabela 1). Como a severidade foi avaliada em frutos que já se encontravam em fase próxima à colheita, os resultados refletiram o acúmulo das infecções ocorridas do início da frutificação até a época da avaliação. Pelas médias de severidade (dados não apresentados), o período de frutificação até maio pode ter proporcionado escape às infecções em frutos, enquanto que o período de frutificação até março foi mais favorável ao acúmulo de lesões nestes órgãos, o que possibilitou discriminar os genótipos. Por outro lado, as folhas possuem menor duração na planta e somente foram avaliadas aquelas localizadas em porção intermediária da copa. Acredita-se que as lesões avaliadas em folhas sejam de infecções ocorridas em época distinta e mais recente daquelas em frutos, o que explica eventuais discrepâncias entre os resultados das avaliações de severidade da doença nestes órgãos. Todavia, não se descarta a possibilidade dos níveis de resistência em folhas diferir dos níveis de resistência à infecção por $A$. caricae em frutos, para distintos genótipos.

\section{Estimativas de capacidade combinatória}

Os valores dos quadrados médios referentes à CGC e CEC foram significativos para as características relacionadas à severidade de pinta-preta em folha e fruto, indicando que os efeitos gênicos aditivos e não aditivos estão envolvidos no controle destas características (Tabela 1). Além disso, para as duas variáveis em estudo, não houve efeito recíproco, ou seja, a direção em que se realiza o cruzamento (qual dos genótipos deverá ser utilizado como genitor masculino ou feminino no cruzamento) não influencia no resultado obtido (Tabela 1). Assim, pode-se levantar hipótese de que a herança para resistência à pinta-preta pode ser controlada por genes nucleares, haja vista que os resultados de um cruzamento e seu recíproco são similares.

Para a severidade de pinta-preta em folha e fruto, as médias dos quadrados dos efeitos praticamente não diferiram entre si (Tabela 1) sugerindo que tanto métodos intrapopulacionais quanto interpopulacionais, como seleção recorrente recíproca de famílias de meios irmãos e de irmãos completos podem ser utilizados. Neste último caso, explorando-se a heterose para caracteres relacionados à resistência de mamoeiro a $A$. caricae.

Significância para CGC indica que efeitos gênicos aditivos estão envolvidos. A existência de efeitos gênicos aditivos para resistência a pinta-preta indica a possibilidade de obtenção de novas cultivares a partir de cruzamentos com os genitores testados, visando melhoria (níveis mais baixos de doença) na obtenção de resistência a $A$. caricae. Uma vez que se trata de resistência, os genótipos que apresentam CGC negativas seriam potencialmente superiores quanto à sua contribuição ao programa de melhoramento.

De acordo com Cruz \& Regazzi (2001), uma baixa estimativa de $G_{i}$, positiva ou negativa, indica que o valor da capacidade geral de combinação do genitor, obtida com base em suas populações híbridas, não difere muito da média geral da população dialélica. Se os valores de i são altos, positivos ou negativos, há indício de que o genitor em questão é muito superior ou inferior aos demais genitores do dialelo, com relação ao desempenho médio das progênies. Os genótipos 'JS12-N', 'Sekati', 'Golden' e 'Sunrise Solo 72/12' apresentaram as menores estimativas de capacidade geral

TABELA 1 - Estimativas dos quadrados médios da capacidade geral de combinação (CGC), da capacidade específica de combinação (CEC), do efeito recíproco (Recíproco) e do erro. Média dos quadrados dos efeitos para severidade da pinta-preta em folha (SPPFo) e no fruto (SPPFr) de mamoeiro, de acordo com o Método 1, Modelo 1 de Griffing

\begin{tabular}{|c|c|c|c|c|c|}
\hline \multirow[t]{3}{*}{ Fonte de variação } & \multirow{3}{*}{$\begin{array}{c}\text { Grau de } \\
\text { liberdade }\end{array}$} & \multicolumn{4}{|c|}{ Quadrado médio } \\
\hline & & \multicolumn{2}{|c|}{ SPPFo } & \multicolumn{2}{|c|}{ SPPFr } \\
\hline & & Mar & Mai & Mar & Mai \\
\hline Genótipo & 63 & $0,0016^{\mathrm{ns}}$ & $0,1925^{* *}$ & $0,2202 * *$ & $0,1983^{\text {ns }}$ \\
\hline C.G.C. & 7 & -- & $1,0148 * *$ & $0,8360 * *$ & --- \\
\hline C.E.C. & 28 & --- & $0,1244 * *$ & $0,1998^{*}$ & --- \\
\hline Recíproco & 28 & --- & $0,0550^{\mathrm{ns}}$ & $0,0867^{\mathrm{ns}}$ & --- \\
\hline Resíduo & 189 & 0,0014 & 0,0523 & 0,1271 & 0,0157 \\
\hline \multicolumn{6}{|c|}{ Média dos quadrados dos efeitos } \\
\hline C.G.C. & & $\overline{---}$ & 0,01504 & 0,011077 & $\overline{---}$ \\
\hline C.E.C. & & --- & 0,01802 & 0,018186 & --- \\
\hline Recíproco & & --- & 0,00035 & $-0,00505$ & --- \\
\hline Resíduo & & --- & 0,05229 & 0,127102 & --- \\
\hline
\end{tabular}

*significativo ao nível de $5 \%$ pelo teste $\mathrm{F}$; ** significativo ao nível de $1 \%$ pelo teste $\mathrm{F}$; ${ }^{\text {ns }}$ não significativo pelo teste $\mathrm{F}$. 
de combinação para severidade de pinta-preta em folha (Tabela 2). Enquanto que para severidade de pinta-preta em fruto, além dos genótipos supracitados, 'Waimanalo' também apresentou estimativa negativa de capacidade geral de combinação (Tabela 2).

Dos genótipos acima, Marin et al. (2006), afirmam que o genótipo 'Waimanalo' apresenta tendência de maior contribuição genética para aumento do peso do fruto. Os mesmos autores afirmam ainda que o genótipo 'Maradol' demonstrou tendência de maior contribuição genética para o aumento do peso do fruto, enquanto 'Sunrise Solo 72/12' poderá ser utilizado visando à obtenção de híbridos com frutos de menor peso.

TABELA 2 - Estimativas dos efeitos de capacidade geral de combinação $\left(G_{i}\right)$ para severidade de pinta-preta estimada em folha (SPPFo), na época 2, e no fruto (SPPFr), na época 1, de oito genitores de mamoeiro. Linhares, ES, 2010

\begin{tabular}{lcc}
\hline \hline \multirow{2}{*}{ Genitor } & \multicolumn{2}{c}{ Capacidade Geral de Combinação } \\
\cline { 2 - 3 } & SPPFo & SPPFr \\
\hline 'Maradol' & 0,002 & 0,039 \\
'JS 12-N' & 0,011 & $-0,057$ \\
'JS 12-4' & 0,035 & 0,221 \\
'Sekati' & 0,271 & $-0,116$ \\
'Waimanalo' & $-0,154$ & 0,100 \\
'Golden' & $-0,032$ & $-0,058$ \\
'Sunrise Solo 72/12' & $-0,103$ & $-0,100$ \\
'São Mateus' & $-0,03$ & $-0,029$ \\
\hline DP (Gi) & 0,027 & 0,042 \\
DP (Gi-Gj) & 0,040 & 0,063 \\
\hline
\end{tabular}

Os efeitos relacionados à CEC enfatizam a importância de interações não aditivas resultantes de complementações gênicas entre os parentais, possibilitando antever respostas de ganho genético com a exploração da heterose (Bastos et al., 2003). No presente estudo, a combinação híbrida mais favorável deve ser, portanto, aquela que apresentar as menores estimativas de capacidade específica de combinação. Os híbridos com valores negativos para severidade de pinta-preta em folha foram oriundos dos cruzamentos: do genitor 'Maradol', com os genótipos 'Waimanalo', 'Sunrise Solo 72/12', 'São Mateus'; do genitor 'JS12-N' com os genótipos 'Maradol', 'Golden', 'Sunrise Solo 72/12'; do genitor 'JS12-4' com o genótipos 'Maradol', 'Waimanalo', 'Sunrise Solo 72/12', 'São Mateus'; do genitor 'Sekati' com os genótipos 'JS12-N', 'Waimanalo', 'Golden', 'Sunrise Solo 72/12'e 'São Mateus'; do genitor 'Waimanalo' com os genótipos'JS12-N', 'Sekati' e 'São Mateus'; do genitor 'Golden' com os genótipos 'Sekati', 'Waimanalo' e 'Sunrise Solo 72/12'; e, do genitor 'São Mateus' com os genótipos 'JS12-N', 'Sekati', 'Golden' e 'Sunrise Solo 72/12' (Tabela 3).

Para a severidade de pinta-preta em frutos os híbridos com valores negativos de capacidade específica de combinação foram oriundos dos cruzamentos: do genitor 'Maradol' com os genótipos 'JS12-N', 'Sekati', 'Sunrise Solo 72/12' e 'São Mateus'; do genitor 'JS12-N' com o genótipo 'Waimanalo'; do genitor 'JS12-4' com os genótipos 'Sekati' e 'Waimanalo'; do genitor 'Sekati' com os genitores 'Waimanalo' e 'São Mateus'; do genitor 'Waimanalo' com os genótipos 'Maradol' ‘JS12-4', 'Sekati', 'Golden', 'Sunrise Solo 72/12' e 'São Mateus'; do genitor 'Golden' com os genótipos 'JS12-4', 'Sekati', 'Sunrise Solo 72/12' e 'São Mateus'; do genitor 'Sunrise Solo 72/12' com os genótipos 'JS12-4', 'Golden' e 'São Mateus'; e, do genitor 'São Mateus' com os genótipos 'JS12-N', 'JS12-4', 'Waimanalo', 'Golden' e 'Sunrise Solo 72/12' (Tabela 3).

Os híbridos (estimativas de CEC para pinta-preta em folha e fruto) 'Maradol x Sunrise Solo 72/12' (-0,070 e -0,027), 'Maradol x São Mateus' (-0,233 e -0,108), 'JS12-4 x Waimanalo' (-0,053 e -0,103), 'Sekati x Waimanalo' (-0,018 e 0,076), 'Sekati x São Mateus’ (-0,152 e -0,032), 'Waimanalo x Sekati' (-0,185 e -0,005), 'Waimanalo x São Mateus' (-0,032 e -0,042), 'Golden x Sekati' (-0,040 e -0,030), 'Golden x Sunrise Solo 72/12' (-0,007 e -0,015), 'São Mateus x JS12-N' (-0,020 e -0,085), 'São Mateus x Golden' (-0,025 e -0,005) e 'São Mateus x Sunrise Solo 72/12' (-0,020 e -0,005) apresentaram resultados promissores para seleção de híbridos com baixos valores de severidade de pinta-preta, tanto em folha quanto no fruto.

Dos híbridos supracitados, Ide et al. (2009) apontaram que, 'Golden x JS12-N', resultou em plantas com alta inserção do primeiro fruto, se comparado com os outros híbridos. Além disso, produziu um número grande de frutos e com peso médio elevado, resultando em plantas com alto rendimento. Porém, apresentou baixos valores de sólidos solúveis totais e firmeza de polpa.

Ide et al. (2009) identificaram ainda que o cruzamento entre o testador 'JS 12' e o genótipo 'São Mateus' pode ser usado em seleção, devido às boas características morfológicas, de rendimento e qualidade. Segundo Vivas et. al. (2011), o referido cruzamento também apresentou baixos valores de CEC para severidade de mancha-dephoma, podendo ser utilizado para redução da severidade desta doença em folha. Para a mesma característica, Vivas et. al. (2011) relatam também o híbrido 'JS12 x Golden' como promissor para redução da severidade de manchade-phoma. Segundo esses autores, o híbrido 'Americano x Waimanalo' se destacou quanto à resistência à: pinta-preta, mancha-de-phoma, oídio (Streptopodium caricae Liberato \& R.W. Barreto) e mancha-chocolate [Colletotrichum gloeosporioides (Penz.) Penz. \& Sacc].

Neste estudo, para as duas variáveis avaliadas, foram observados valores positivos e negativos de CEC, o que segundo Cruz \& Vencovsky (1989) indica a existência de desvio de dominância, na qual se verificam genes que aumentam a expressão do caráter, e outros igualmente dominantes, que as reduzem. Desta forma, vislumbrase a possibilidade de seleção de combinações híbridas potencialmente promissoras no que tange a resistência à 
M. Vivas et al.

TABELA 3 - Estimativas dos efeitos de capacidade especifica de combinação $\left(\mathrm{S}_{\mathrm{ii}}\right.$ e $\left.\mathrm{S}_{\mathrm{ij}}\right)$, resultantes do cruzamento entre genitores de mamão quanto à severidade da pinta-preta estimada em folha (SPPFo), na época 2, e no fruto (SPPFr) na época 1. Linhares, ES, 2010

\begin{tabular}{|c|c|c|c|c|}
\hline \multirow[t]{2}{*}{ Híbrido Avaliado } & \multicolumn{2}{|c|}{ C.E.C. em $F_{1} s$} & \multicolumn{2}{|c|}{ C.E.C. recíproco } \\
\hline & SPPFo & SPPFr & SPPFo & SPPFr \\
\hline 'Maradol x JS 12-N' & 0,136 & $-0,100$ & $-0,005$ & 0,060 \\
\hline 'Maradol x JS 12-4' & 0,027 & 0,277 & $-0,100$ & 0,435 \\
\hline 'Maradol x Sekati' & 0,096 & $-0,076$ & 0,005 & 0,015 \\
\hline 'Maradol x Waimanalo' & $-0,074$ & 0,109 & 0,050 & $-0,085$ \\
\hline 'Maradol x Golden' & 0,068 & 0,101 & 0,025 & 0,060 \\
\hline 'Maradol x Sunrise Solo 72/12' & $-0,070$ & $-0,027$ & 0,065 & 0,070 \\
\hline 'Maradol x São Mateus' & $-0,223$ & $-0,108$ & 0,195 & 0,090 \\
\hline 'JS 12-N x JS 12-4' & 0,027 & 0,029 & 0,110 & 0,120 \\
\hline 'JS 12-N x Sekati' & 0,147 & 0,056 & $-0,025$ & 0,030 \\
\hline 'JS 12-N x Waimanalo' & 0,107 & $-0,170$ & $-0,020$ & 0,010 \\
\hline 'JS 12-N x Golden' & $-0,111$ & 0,023 & 0,115 & 0,005 \\
\hline 'JS 12-N x Sunrise Solo 72/12' & $-0,070$ & 0,070 & 0,015 & 0,040 \\
\hline 'JS 12-N x São Mateus' & 0,043 & 0,144 & $-0,020$ & $-0,085$ \\
\hline 'JS 12-4 x Sekati' & 0,162 & $-0,048$ & 0,035 & 0,135 \\
\hline 'JS 12-4 x Waimanalo' & $-0,053$ & $-0,103$ & 0,005 & $-0,095$ \\
\hline 'JS 12-4 x Golden' & 0,135 & 0,134 & 0,015 & $-0,115$ \\
\hline 'JS 12-4 x Sunrise Solo 72/12' & $-0,044$ & 0,016 & 0,105 & $-0,055$ \\
\hline 'JS 12-4 x São Mateus' & $-0,067$ & 0,285 & 0,165 & $-0,125$ \\
\hline 'Sekati x Waimanalo’' & $-0,018$ & $-0,076$ & $-0,185$ & $-0,005$ \\
\hline 'Sekati x Golden' & $-0,266$ & 0,037 & $-0,040$ & $-0,030$ \\
\hline 'Sekati x Sunrise Solo 72/12' & $-0,050$ & 0,074 & 0,095 & 0,015 \\
\hline ‘Sekati x São Mateus’ & $-0,152$ & $-0,032$ & $-0,035$ & $-0,032$ \\
\hline 'Waimanalo x Golden' & 0,004 & $-0,144$ & $-0,005$ & 0,035 \\
\hline 'Waimanalo x Sunrise Solo 72/12' & 0,015 & $-0,107$ & 0,005 & 0,020 \\
\hline ‘Waimanalo x São Mateus’' & $-0,032$ & $-0,043$ & 0,120 & $-0,015$ \\
\hline 'Golden x Sunrise Solo 72/12' & $-0,007$ & $-0,015$ & 0,095 & $-0,005$ \\
\hline 'Golden x São Mateus' & 0,130 & $-0,085$ & $-0,025$ & $-0,005$ \\
\hline 'Sunrise Solo 72/12 x São Mateus' & 0,027 & $-0,043$ & $-0,020$ & $-0,005$ \\
\hline DP (Sij) e DP (Rij) & 0,071 & 0,111 & 0,081 & 0,126 \\
\hline DP (Sij-Skl) e DP (Rij-Rkl) & 0,099 & 0,154 & 0,114 & 0,178 \\
\hline
\end{tabular}

pinta-preta, com potencial para se produzir frutos de maior qualidade e que sejam menos dependentes da aplicação de fungicidas.

\section{Estimativas de heterose}

Para a severidade de pinta-preta em folhas e frutos, observou-se efeito significativo de todas as fontes de variação testadas (genótipo, época de avaliação e interação entre os dois fatores). Como feito para análise da capacidade combinatória, a heterose foi estimada apenas nas épocas de avaliação em que se constatou efeito significativo de genótipo, ou seja, para severidade em frutos, na primeira época, e para severidade em folhas, na segunda época de avaliação.

As cultivares mais exploradas de mamão no Brasil são classificadas em dois grupos, 'Solo', com frutos menores, e 'Formosa', com frutos maiores. Em função da acentuada distinção no tamanho dos frutos, estes grupos usualmente são considerados heteróticos. Os grupos heteróticos são constituídos de genótipos com composição genética similar para uma dada característica e que quando há cruzamento entre linhagens de dois grupos diferentes, observa-se comumente elevado efeito heterótico (heterose). Entretanto, contrariamente ao esperado, nas estimativas de heterose obtidas para resistência a pinta-preta em folha, não se observou tendência de efeito heterótico nos cruzamentos que envolvem os genótipos dos dois grupos. Já, para híbridos provenientes dos cruzamentos entre os genitores do grupo 'Solo', observou-se efeito de heterose em todos os híbridos (Tabela 4). Por outro lado, todos os híbridos provenientes dos cruzamentos dentro do grupo 'Formosa' não superaram as médias dos seus genitores. Sabe-se que a manifestação da heterose dá-se em função da distância genética entre os genitores. Esta divergência refere-se à diferença na frequência dos alelos. Quanto mais distante os genitores, melhor é o híbrido (Hallauer \& Miranda Filho, 1981). Conclui-se, portanto, que os genótipos utilizados nos cruzamentos, notadamente do grupo 'Solo', portam alelos distintos que se complementaram na formação dos híbridos, conferindo maiores níveis de resistência a pinta-preta em folha.

Para severidade da pinta-preta em fruto, não se observou tendências de heterose entre os grupos 'Solo' e 'Formosa'. Todavia alguns genótipos apresentam-se como 
mais promissores para hibridação, visto que a maioria dos cruzamentos que os envolviam geraram híbridos superiores, ou seja, com menores valores de severidade em relação aos genitores. Considerando o desempenho dos híbridos, os genitores do grupo 'Formosa' 'Maradol' e 'Sekati' e os genitores do grupo 'Solo' 'Waimanalo' e 'São Mateus' foram os que apresentaram um número maior de híbridos cujas médias de severidade foram inferiores às médias dos seus progenitores (Tabela 5).

Considerando conjuntamente a severidade de pintapreta em folha e fruto, os híbridos que obtiveram estimativas negativas de heterose para as duas variáveis foram: 'Maradol x Waimanalo', 'Sekati x Waimanalo', 'Sekati x São Mateus', 'Waimanalo x Golden'; 'Waimanalo x
Sunrise Solo 72-12', 'Waimanalo x São Mateus', 'Golden x Waimanalo', 'Golden x Sunrise Solo 72-12', 'Golden x São Mateus', 'Sunrise Solo 72-12 x Maradol', 'Sunrise Solo 7212 x Waimanlo', 'Sunrise Solo 72-12 x São Mateus', 'São Mateus x Maradol', 'São Mateus x Sekati', 'São Mateus x Waimanalo' e 'São Mateus x Golden'.

Dos híbridos supracitados Marin et al. (2006) apontam os genótipos 'Maradol' e 'Waimanalo' com tendência para aumento do peso do fruto, enquanto 'Sunrise Solo $72 / 12$ ' poderá ser utilizado visando à obtenção de híbridos com menor peso. Já o genótipo 'São Mateus' pode contribuir para a redução na altura da planta.

Os resultados obtidos no presente estudo evidenciam que a exploração da heterose na cultura do mamoeiro para

TABELA 4 - Estimativa de heterose (HMP) e heterobeltiose (HPS) para severidade da pinta-preta avaliada em folha, na época 2, em híbridos de mamoeiro derivados de cruzamentos entre genitores do grupo 'Solo' e 'Formosa' em esquema de dialelo completo. Linhares, ES, 2010

\begin{tabular}{|c|c|c|c|c|c|c|c|c|c|}
\hline Genitor & & 'Maradol' & 'JS12-N' & 'JS12-4' & 'Sekati' & 'Waimanalo' & 'Golden' & 'SS 72-12' & 'São Mateus' \\
\hline \multirow[t]{2}{*}{ 'Maradol' } & HMP & -- & 74,26 & 0,00 & 5,14 & $-21,77$ & 11,78 & $-27,76$ & $-32,61$ \\
\hline & MPS & -- & 207,79 & 24,43 & 67,69 & 39,47 & 20,00 & $-23,86$ & $-20,51$ \\
\hline \multirow[t]{2}{*}{ 'JS12-N' } & HMP & 76,47 & -- & 140,38 & 34,52 & 105,23 & 40,08 & $-5,14$ & 4,68 \\
\hline & MPS & 211,69 & -- & 224,68 & 340,26 & 106,58 & 124,68 & 55,84 & 132,47 \\
\hline \multirow[t]{2}{*}{ 'JS12-4' } & HMP & 49,08 & 58,65 & -- & 36,20 & 8,21 & 60,13 & 15,31 & 10,10 \\
\hline & MPS & 85,50 & 114,29 & -- & 190,08 & 47,37 & 83,97 & 35,11 & 66,41 \\
\hline \multirow[t]{2}{*}{ 'Sekati' } & HMP & 3,54 & 42,86 & 25,45 & -- & $-42,74$ & $-48,74$ & $-12,44$ & $-42,77$ \\
\hline & MPS & 65,13 & 367,53 & 167,18 & -- & 89,47 & $-10,00$ & 50,00 & $-25,28$ \\
\hline \multirow[t]{2}{*}{ 'Waimanalo' } & HMP & $-51,29$ & 122,22 & 4,35 & 16,50 & -- & $-17,07$ & $-32,54$ & $-17,89$ \\
\hline & MPS & $-13,16$ & 123,68 & 42,11 & 285,53 & -- & 34,21 & 11,84 & 84,21 \\
\hline \multirow[t]{2}{*}{ 'Golden' } & HMP & 0,27 & $-35,22$ & 50,83 & $-38,36$ & $-13,01$ & -- & $-6,94$ & $-10,34$ \\
\hline & MPS & 7,65 & 3,90 & 73,28 & 8,24 & 40,79 & -- & $-5,29$ & 14,71 \\
\hline \multirow[t]{2}{*}{ 'SS 72-12' } & HMP & $-32,08$ & $-13,83$ & $-39,41$ & $-37,98$ & $-36,51$ & $-52,02$ & -- & $-42,40$ \\
\hline & MPS & $-28,41$ & 41,56 & $-29,01$ & 6,25 & 5,26 & $-51,18$ & -- & $-27,84$ \\
\hline \multirow[t]{2}{*}{ 'São Mateus' } & HMP & $-63,48$ & 14,04 & $-56,57$ & $-34,39$ & $-75,37$ & $-0,23$ & $-34,24$ & -- \\
\hline & MPS & $-56,92$ & 153,25 & $-34,35$ & $-14,34$ & $-44,74$ & 27,65 & $-17,61$ & -- \\
\hline
\end{tabular}

TABELA 5 - Estimativa de heterose (HMP) e heterobeltiose (HPS) para severidade da pinta-preta avaliada em fruto, na época 1, em híbridos de mamoeiro derivados de cruzamentos entre genitores do grupo 'Solo' e 'Formosa', em esquema de dialelo completo. Linhares, ES, 2010

\begin{tabular}{|c|c|c|c|c|c|c|c|c|c|}
\hline Genitor & & 'Maradol' & 'JS12-N' & 'JS12-4' & 'Sekati' & 'Waimanalo' & 'Golden' & 'SS 72-12' & 'São Mateus' \\
\hline \multirow[t]{2}{*}{ 'Maradol' } & HМP & -- & 147,62 & 1748,00 & $-12,20$ & $-30,17$ & 504,65 & 214,29 & 265,00 \\
\hline & MPS & -- & 642,86 & 2980,00 & 200,00 & 300,00 & 1525,00 & 842,86 & 1360,00 \\
\hline \multirow[t]{2}{*}{ 'JS12-N' } & HMP & $-76,19$ & -- & 1718,18 & 484,62 & $-84,45$ & 433,33 & 700,00 & 983,33 \\
\hline & MPS & $-28,57$ & -- & 2757,14 & 533,33 & 314,29 & 471,43 & 700,00 & 1200,00 \\
\hline \multirow[t]{2}{*}{ 'JS12-4' } & НМР & 368,00 & 836,36 & -- & 1357,14 & $-35,43$ & 1178,26 & 872,73 & 2050,00 \\
\hline & MPS & 680,00 & 1371,43 & -- & 2450,00 & 720,00 & 1737,50 & 1428,57 & 4200,00 \\
\hline \multirow[t]{2}{*}{ 'Sekati' } & HMP & $-60,98$ & 115,38 & 328,57 & -- & $-80,11$ & 0,00 & 284,62 & $-9,09$ \\
\hline & MPS & 33,33 & 133,33 & 650,00 & -- & 516,67 & 16,67 & 316,67 & 0,00 \\
\hline \multirow[t]{2}{*}{ 'Waimanalo' } & HMP & 3,74 & $-88,74$ & 4,99 & $-77,96$ & -- & $-73,80$ & $-78,55$ & $-56,33$ \\
\hline & MPS & 494,29 & 200,00 & 1233,33 & 583,33 & -- & 512,50 & 471,43 & 1520,00 \\
\hline \multirow[t]{2}{*}{ 'Golden' } & HMP & 286,05 & 380,00 & 1995,65 & 371,43 & $-88,77$ & -- & $-60,00$ & $-38,46$ \\
\hline & MPS & 937,50 & 414,29 & 2912,50 & 450,00 & 162,50 & -- & $-57,14$ & $-20,00$ \\
\hline \multirow[t]{2}{*}{ 'SS 72-12' } & HMP & $-33,33$ & 228,57 & 1281,82 & 84,62 & $-88,20$ & 20,00 & -- & $-50,00$ \\
\hline & MPS & 100,00 & 228,57 & 2071,43 & 100,00 & 214,29 & 28,57 & -- & $-40,00$ \\
\hline \multirow[t]{2}{*}{ 'São Mateus' } & HМР & $-40,00$ & 2116,67 & 3040,00 & $-45,45$ & $-50,40$ & $-7,69$ & 0,00 & -- \\
\hline & MPS & 140,00 & 2560,00 & 6180,00 & $-40,00$ & 1740,00 & 20,00 & 20,00 & -- \\
\hline
\end{tabular}


resistência a pinta-preta, possibilitará ganhos genéticos significativos e esses ganhos poderão advir tanto de cruzamentos inter como intragrupo heterótico.

\section{AGRADECIMENTOS}

À Fundação Carlos Chagas Filho de Amparo à Pesquisa do Estado do Rio de Janeiro - FAPERJ, à Universidade Estadual do Norte Fluminense Darcy Ribeiro - UENF, e à Caliman Agrícola SA pelo suporte financeiro e logístico.

\section{REFERÊNCIAS BIBLIOGRÁFICAS}

Agrianual (2011) Anuário da agricultura brasileira. São Paulo SP. FNP Consultoria e Comércio.

Bastos IT, Barbosa MHP, Cruz CD, Burnquist WL, Bressiani JA, Silva FL (2003) Análise dialélica em clones de cana-de-açúcar. Bragantia 62:199-206.

Cruz CD (2006) Programa Genes, biometria. Viçosa MG. Editora UFV.

Cruz CD, Regazzi AJ (2001) Modelos biométricos aplicados ao melhoramento genético. Viçosa MG. Editora UFV.

Cruz CD, Vencovsky R (1989) Comparação de alguns métodos de análise dialélica. Revista Brasileira de Genética 12:425-438.

Dianese AC, Blum LEB, Dutro JB, Lopes LF, Sena MC, Freitas LF, Yamanishi OK (2007) Reação de genótipos de mamoeiro à varíola e à podridão-do-pé. Fitopatologia Brasileira 32:419-423.

Falconer DS (1987) Introdução à genética quantitativa. Viçosa MG. Editora UFV.

Griffing BA (1956) Concept of general and specific combining ability in relation to diallel crossing systems. Australian Journal of Biological Sciences 9:463-493.

Hallauer AR, Miranda Filho JB (1981) Quantitative genetics in maize breeding. Ames Iowa. Iowa State University Press.

Ide CD, Pereira MG, Viana AP, Pereira TNS (2009) Use of testers for combining ability and selection of papaya hybrids. Crop Breeding and Applied Biotechnology 9:60-66.

Koutsika-Sotiriou MS, Karagounis CA (2005) Assessment of maize hybrids. Maydica 50:63-70.

Liberato JR, McTaggart AR, Shivas RG (2007) Asperisporium black spot of papaya (Asperisporium caricae). Pest and Diseases Image Library. Available at: http://www.padil.gov.au. 2007. Accessed on: 02/02/2012

Liberato JR, Zambolim L (2002) Controle das doenças causadas por fungos, bactérias e nematóides em mamoeiro. In: Zambolim L, Vale FXR, Monteiro AJA, Costa H (Eds.) Controle de doenças de plantas: Fruteiras. Viçosa MG. Suprema Gráfica e Editora. pp. 1023-1138

Marin SLD, Pereira MG, Amaral Junior AT, Martelleto LAP, Ide CD (2006) Partial diallel to evaluate the combining ability for economically important traits of papaya. Scientia Agrícola 63:540-546.

Rezende JAM, Martins MC (2005) Doenças do mamoeiro (Carica papaya L.). In: Kimati H, Amorim L, Rezende JAM, Bergamin Filho A, Camargo LEA(Eds). Manual de fitopatologia: Doenças das plantas cultivadas. São Paulo SP. Agronômica Ceres. pp.435-443.

Santos MC, Barreto M (2003) Estudo epidemiológico da varíola do mamoeiro em cultivares submetidos a tratamento com fungicidas. Summa Phytopathologica 29:141-146.

Suzuki MS, Zambolim L, Liberato JR (2007) Progresso de doenças fúngicas e correlação com variávies climáticas em mamoeiro. Summa Phytopathologica 33:167-177.

Vivas M, Terra CEPS, Silveira SF, Fontes RV, Pereira MG (2010) Escala diagramática para avaliação da severidade de pinta-preta em frutos de mamoeiro. Summa Phytopathologica 36:161-163.

Vivas M, Silveira SF, Terra CEPS, Pereira MG (2011) Testers for combining ability and selection of papaya hybrids resistant to fungal diseases. Crop Breeding and Applied Biotechnology 11:3642.

TPP 519 - Recebido 7 Março 2012 - Aceito 17 Junho 2012

Editor de Seção: Marciel J. Stadnik 